\title{
Maternal Anemia and its Impact on Nutritional Status of Children Under the Age of Two Years
}

\author{
Aisha Iftikhar*1, Attia Bari², Fatima Zeeshan ${ }^{3}$, Uzma Jabeen ${ }^{4}$, Qaisar Masood ${ }^{5}$ and Ahsan Waheed \\ Rathore $^{6}$
}

1-4,6Department of Pediatric Medicine, The Children's Hospital and The Institute of Child Health, Pakistan

${ }^{5}$ Consultant Pediatrician, Nawaz Sharif Social Security Hospital, Pakistan

Received: May 28, 2018; Published: June 11, 2018

*Corresponding author: Aisha Iftikhar, 342 Kareem Block, Allama Iqbal Town Lahore, Pakistan

Abstract

Objective: To assess the frequency of anemia in mothers accompanying children admitted in General Medical Ward of The Children's Hospital Lahore and to determine its association with the growth parameters of their children under two years of age.

Methodology: Total 228 children admitted in General Medical Ward with acute illness along with their mothers were included in the study. Blood sample of their mothers for Hb level was taken. Height and weight of children were plotted on WHO Growth Charts. Anemia was defined according to World Health Organization (WHO) as hemoglobin level of $<12 \mathrm{~g} / \mathrm{dL}$ in non-pregnant women. Data was analyzed using SPSS version 20.

Results: Out of 228 patients 147 (64.5\%) were males. The mean age of children was $8.7 \pm 6.6$ months. Mean maternal age was $26 \pm 5.3$ years. Anemia was present in 154 (67.5 \%) mothers. Mean maternal Hb was $10.6 \pm 1.6$ gm/dl. Forty-nine percent children were severely underweight (Z score <-3) and 37 (16.2\%) were falling on median. Severely stunted children were 92 (40.4\%) (Z score <-3) while 43 (18.9\%) were at median. Low weight for age and Length/Height for age of children was significantly associated with maternal anemia ( $p=0.017)$, $(p=0.05)$ respectively. Other maternal factors affecting the child's nutritional status and growth parameters were multi-parity, general maternal health and education level with $p$ value of $0.005,0.01$ and 0.04 respectively.

Conclusion: Maternal anemia has a significant effect on nutritional status of young children leading to stunting and underweight. Associated maternal factors were maternal education, multi-parity and poor maternal health.

Keywords: Maternal anemia; Stunted children; Underweight children

\section{Introduction}

Developing countries are bearing huge burden of anemia and it is persisting as a public health issue worldwide [1]. Women of child bearing age, pregnant women and children are considered as high risk population group [2]. In Pakistan 52\% of pregnant women $32 \%$ of women of childbearing age are victims of anemia [3]. Worldwide more than 50\% pregnant women and 30\% of all women of childbearing age suffer from anemia [4]. In developing world although iron deficiency accounts for half of cases but other nutrient deficiencies like (vitamin A, riboflavin, folic acid, and vitamin B12), parasitic and infectious diseases also play significant role[5,6]. Consequences of anemia are diverse [7]. In pregnancy, detrimental effects associated with anemia lead to low birth weight babies [8] and pre-term deliveries [9]. Substantial number of cases of anemia in infancy and childhood are due to maternal iron deficiency. Anemia causes impaired physical growth of infants, preschool and school aged children [10].
Anemic mothers have significant diminution in working capacity causing difficulties in performing house hold chores and child care, thus affecting growth para meters of children of anemic mothers [11]. So, the hazardous effects of anemia in pregnancy on infant's growth multiply and intensify when anemic mothers cannot give proper attention and care due to their own ill health. With each pregnancy, this problem magnifies and in next pregnancy and lactation phase she suffers iron deficiency because of inadequate pre-pregnancy iron reserves. Thus, anemia is a life-long burden for women one which also endangers their children's growth parameters and nutritional status [12]. Most of our mothers are suffering from the adverse effects of anemia. This aspect of maternal health is being ignored. Previous studies have elucidated risk factors for child under nutrition like maternal behaviors, dietary factors and environmental factors etc [13]; but research on this neglected factor like maternal anemia, which might also predispose a child to increased risk of growth impairment is lacking. 
We conducted our research on children from 2 months to two years as maternal factors have an immediate effect on a child's life during this period of enormous growth. Through this study we planned to document in literature that maternal anemia can be a risk factor in growth parameter impairment of their children even up to age of infancy and beyond.

\section{Methodology}

This was a hospital based descriptive cross-sectional study, conducted at The Children's Hospital and The Institute of Child Health (ICH) Lahore. Approval from Institutional Review Board of The ICH was taken. Children from aged two months to two years admitted to General Medical Ward of for any acute illness like pneumonia, acute diarrhea, febrile fits were included in the study along with accompanying mothers. Consent was taken from mothers before enrolling them in study. Children of $<2$ months and $>2$ years and those having any chronic disease were excluded. Information about demographic profile, weight, height, health status, parity and mother's education status were determined. No of children and number of under five children were recorded. Father's education status and monthly income was also inquired. Child's age, height or length (in less than 1year) and weight of the child was documented and was plotted on WHO - Z Score Charts. Their weight, height or length (in less than1year) was measured by our appropriately trained doctor. $5 \mathrm{cc}$ venous blood sample was taken from mothers for complete blood count including hemoglobin, red blood cells count and hematocrit.

After collection blood was immediately transferred into labeled and prepared tubes containing EDTA or heparin and sent to laboratory for hemoglobin estimation. Anemia was defined according to World Health Organization (WHO) hemoglobin level of $<12 \mathrm{~g} / \mathrm{dL}$ in non- pregnant adult woman [14]. The information collected was analyzed by using statistical software SPSS -20 . The quantitative variables like age, height, weight, family size, no of Table 1: Maternal factors affecting weight of children. children under five and Hb level was presented as mean and SD. Variables like maternal education level and father's education level was presented by calculating frequency and percentages. Chi square test was applied and $p$ value $<0.05$ was considered significant.

\section{Results}

A total of 228 patients were included in this study. Males 147 (64.5\%) out-numbered the females 81 (35.5\%), with a male to female ratio of $2: 1$. The mean age of children was $8.7 \pm 6.6$ months. The range of maternal age was 18 to 43 years with mean age of $26.8 \pm 5.302$ years (Table 1). Out of 228 mothers 79 (34.6\%) were of less than 25 years and 149 (65.4\%) were between 25-45years. Only 74 (32.4\%) mothers had hemoglobin level at or above $12 \mathrm{gm} /$ $\mathrm{dl}$ and 154 (67.5 \%) were anemic. (Figure 1) Mean maternal $\mathrm{Hb}$ was $10.67 \pm 1.6$ with the range of $6-15 \mathrm{gm} / \mathrm{dl}$. According to WHO Z Scoring 112 (49.1\%) children were severely underweight (Z score $<-3$ ) and only 37 children (16.2\%) were on median shown in Figure 2. Severely stunted children $(<-3)$ were found to be $92(40.4 \%)$ and $43(18.9 \%)$ were having appropriate height for age i.e. at median, illustrated in Figure 3.

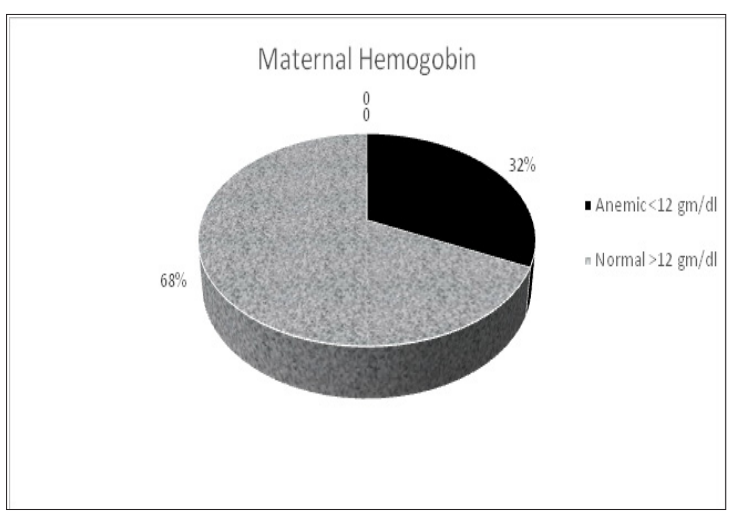

Figure 1: Maternal Hemoglobin Levels.

\begin{tabular}{|c|c|c|c|c|c|c|c|}
\hline Factors & & $<3$ to -3 & $<-2$ to -2 & $<-1$ to -1 & Median or > & Total & P-value \\
\hline \multirow{2}{*}{ Hb level } & Normal & $39(34.8 \%)$ & $13(36.1 \%)$ & $18(41.9 \%)$ & $4(10.8 \%)$ & 74(32.5\%) & \multirow{2}{*}{0.017} \\
\hline & Anaemic & 73(s65\%) & $23(63.9 \%)$ & 25 (58.1\%) & 33 (89.2\%) & $154(67.5 \%)$ & \\
\hline \multirow{3}{*}{$\begin{array}{l}\text { General } \\
\text { Maternal } \\
\text { health }\end{array}$} & Good & $19(17 \%)$ & $12(33.3 \%)$ & $14(32.6 \%)$ & $8(21.6 \%)$ & $53(23.2 \%)$ & \multirow{3}{*}{0.018} \\
\hline & Average & 85 (75.9\%) & $17(47.2 \%)$ & 27 (62.8\%) & $27(73.0 \%)$ & $156(68.4 \%)$ & \\
\hline & Poor & $8(7.1 \%)$ & $7(19.4 \%)$ & $2(4.7 \%)$ & $2(5.4 \%)$ & $19(8.3 \%)$ & \\
\hline \multirow{3}{*}{ Parity } & Upto 3 & $48(42.9 \%)$ & $26(72.2 \%)$ & $30(69.8 \%)$ & $26(70.3 \%)$ & $130(57.0 \%)$ & \multirow{3}{*}{0.005} \\
\hline & 5-Apr & $42(37.5 \%)$ & 7 (19.4 \%) & $10(23.3 \%)$ & 7 (18.9\%) & $66(28.9 \%)$ & \\
\hline & $>5$ & $22(19.6 \%)$ & $3(8.3 \%)$ & $3(7.0 \%)$ & $4(10.8 \%)$ & 32 & \\
\hline \multirow{5}{*}{$\begin{array}{l}\text { Maternal } \\
\text { education }\end{array}$} & Illiterate & $69(61.6 \%)$ & $20(55.6 \%)$ & $20(46.5 \%)$ & $19(51.4 \%)$ & $128(56.1 \%)$ & \multirow{5}{*}{0.04} \\
\hline & Primary & $23(20.5 \%)$ & $6(16.7 \%)$ & $8(18.6 \%)$ & $14(37.8 \%)$ & $51(22.4 \%)$ & \\
\hline & Secondary & 15 (13.4\%) & $10(27.8 \%)$ & $13(30.2 \%)$ & $3(8.1 \%)$ & $41(18 \%)$ & \\
\hline & Graduate & $5(4.5 \%)$ & $0(0 \%)$ & $2(4.7 \%)$ & $1(2.7 \%)$ & $8(3.5 \%)$ & \\
\hline & & $49.10 \%$ & $15.80 \%$ & $18.90 \%$ & $16.20 \%$ & $100 \%$ & \\
\hline
\end{tabular}




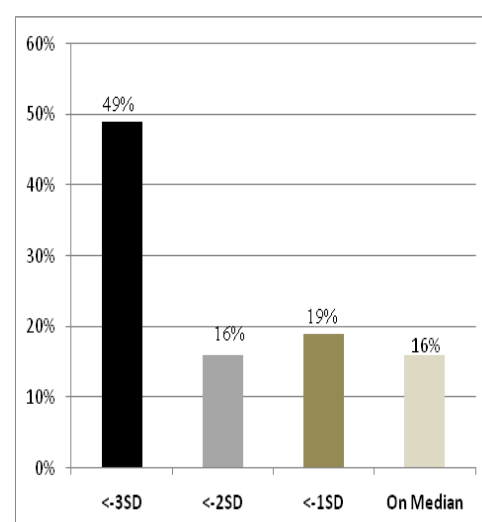

Figure 2: Pattern of Weight for Age of Children.

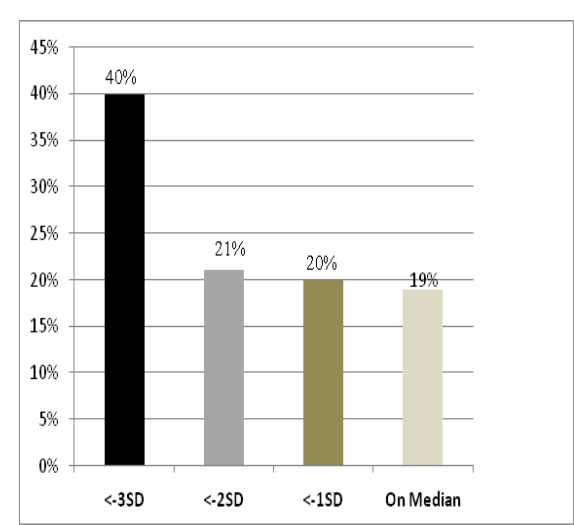

Figure 3: Pattern of Height for Age of Children.

We found significant association between weight for age and height or length for age of the children with maternal $\mathrm{Hb}$ level with $p$ value of $(0.017),(p=0.06)$ respectively. During the study, other parameters were also studied like parity, number of under 5 children, general maternal health, mother's and father's education level and father's income. It was not astonishing for us that parameters related to mothers like parity, general maternal health and mother education level had a significant effect on children's weight with $p$ vale of $0.005,0.01$ and 0.04 respectively.

\section{Discussion}

We assessed the frequency of anemia in mothers of children admitted in General Medical Ward of The Children's Hospital and determined its association with the growth parameters of their children.The demographic analysis shows a high proportion of patients having male gender i.e. 147 (64.5\%), with a male to female ratio of 2:1. This may signify the male dominance and sex discrimination in South East Asia. Male children are preferred in all aspects and it is also true in medical aid seeking behavior. Boys are brought to hospital more often than girls. A preponderance of males with $52.5 \%$ boys and $47.5 \%$ girls was noted in another study from Pakistan [15]. In our study, it was revealed that 154 (67.5\%) mothers were anemic. These results are comparable to an Indian study where Shoba Rao has documented seventy-seven percent of the childbearing age women were anemic $(\mathrm{Hb}<12 \mathrm{~g} /$ dl). This slight difference may be justified as this Indian study was based on rural population [16]. Whereas several studies in Ethiopia have shown the prevalence of anemia in women of reproductive age group ranging from $16.6 \%$ to $30.4 \%$, A study done in Abbottabad (Pakistan) on prevalence of anemia in child bearing age women has shown almost similar results as in our study i.e. 60\% [17].

We found that 112 (49.1\%) children were severely underweight (Z score $<-3$ ) while 36 (15.8\%) children had weight for age <-2 and $43(18.9 \%)$ had weight for age $(<-1$ to $<$ median) however 37 $(16.2 \%)$ were on median and more than median. Almost similar percentage of children i.e. (15.7\%) have been shown in Child Nutrition Status by Region, 2010 results for moderate malnutrition. But percentage of children having severe malnutrition in our study is quite high than shown in 2010 report. i.e. (49.1\% in our study but $23.7 \%$ in 2010, 2011 survey) [18]. This difference may be due to time elapsed between two studies secondly our data was hospital based which may have increased proportion of severely underweight children. This figure may raise the issue that appropriate interventions to combat the problem of malnutrition in Pakistan by the policy makers is not started yet which has resulted in such a great difference.

In this particular study, we found severely stunted children (< -3) to be $92(40.4 \%)$ while $47(20.6 \%)$ were moderately stunted $(<-2)$ and $46(20.2 \%)$ falling at $<-1$. It was found that $43(18.9 \%)$ children were at median or above median. Almost similar results were reported in NNS-2011 and Child Nutritional status 2010 about severely and moderately stunted children i.e. $43.7 \%$ and $20.2 \%$ respectively [19]. We found significant association between weight for age and height or length for age of the children with maternal Hb level. Effect of maternal anemia on growth of children was also observed by Singla where effect on fetal growth was observed in all parameters [20]. Statistical significant association was also found between maternal anemia and low birth weight babies by Ahmad [21]. This powerful association between weight for age and height and length for age of the children with maternal $\mathrm{Hb}$ level emphasizes that child wellbeing is intimately embedded with maternal serenity and contentment.

During the study, other parameters were also studied like parity, number of under 5 children, general maternal health, mother's and father's education level and father's income. It was not astonishing for us that parameters related to mothers like parity, general maternal health and mother education level had a significant effect on children's weight with $\mathrm{p}$ vale of $0.005,0.01$ and 0.04 respectively. Various studies done in different parts of world also endorse this fact for example a study done in Kenya has shown a strong positive and significant association with growth parameters of children with parity of mother although in this study other parameters like maternal education, mother marital status and maternal education level were also studied and found these too are positively associated [22]. A Nigerian study has also shown a strong association of maternal health with the growth para meters of children [23]. A pooled analysis by O.Yaw Addo from 5 birth cohorts (Brazil, Guatemala, India, the Philippines, and South Africa) has shown positive co-relation between maternal height and growth para meters of their children [24]. Similarly, OyaYucel, 
Nursan Dede Cinar has validated in his attention-grabbing research that maternal body mass index which is the best indicator of health has direct impact on growth para meters of children [25].

\section{Conclusion}

Maternal anemia has a significant effect on nutritional status of children leading to stunting and underweight. Staying wellnourished during this period of enormous growth as well as vulnerability can pave the way for a strong, healthy, productive future. It is imperative to improve general health and hemoglobin level of the women at child-bearing age, to protect children from being growth retarded.

\section{References}

1. World Wide prevelence of anaemia 1993-2005, Atlanta.

2. Miller JL (2013) Iron deficiency anemia: a common and curable disease. Cold Spring HarbPerspect Med 3(7).

3. Prevalence of anemia among pregnant women (\%), The World Bank, USA.

4. Steven A, Finucane M, DeRegil L, Paciorek J, Flaxman SR, et al. (2015) Global, regional, and national trends in haemoglobin concentration and prevalence of total and severe anaemia in children and pregnant and non-pregnant women for 1995-2011: a systematic analysis of population-representative data. Lancent Global Heal 1(1): 1-14.

5. Abbaspour N, Hurrell R, Kelishadi R (2014) Review on iron and its importance for human health. Journal of Research in Medical Sciences 19: 164-174.

6. Alquaiz AM, Gad Mohamed A, Khoja T a M, Alsharif A, Shaikh SA, et al. (2013) Prevalence of anemia and associated factors in child bearing age women in riyadh, saudiarabia. J Nutr Metab p. 1-7.

7. ElShazley MK, Ibrahim AG, Masoud GM (1996) Risk factors of anemia among women in the child bearing period and preschool children in Alexandria. J Egypt Public Health Assoc 71(3-4): 229-241.

8. Nair M, Choudhury MK, Choudhury SS, Kakoty SD, Sarma UC, et al. (2016) Association between maternal anaemia and pregnancy outcomes: a cohort study in Assam, India, p. 1-10.

9. Raza N, Sarwar I, Munazza B, Ayub M, Suleman M (2011) Assessment of iron deficiency in pregnant women by determining iron status. J Ayub Med Coll Abbottabad 23(2).

10. Anemia in pregnancy, GLOWM, UK.
11. Kalaivani K (2009) Prevalence \& consequences of anaemia in pregnancy. Indian J Med Res130(5): 627-633.

12. Terefe B, Birhanu A, Nigussie P, Tsegaye A (2015) Effect of Maternal Iron Deficiency Anemia on the Iron Store of Newborns in Ethiopia. Anemia p. 1-6.

13. Subramanian SV, Ackerson LK, Smith GD, John NA (2009) Association of Maternal Height With Child Mortality, Anthropometric Failure, and Anemia in India. JAMA. American Medical Association 301(16): 16911701.

14. (2011) Haemoglobin concentrations for the diagnosis of anaemia and assessment of severity. Vitamin and Mineral Nutrition Information System. Geneva, World Health Organization, WHO, USA.

15. Mushtaq MU, Gull S, Mushtaq K, Abdullah HM, Khurshid U, et al. (2012) Height, weight and BMI percentiles and nutritional status relative to the international growth references among Pakistani school-aged children. BMC Pediatr 12(12).

16. Rao S, Joshi S, Bhide P, Puranik B, Kanade A (2011) Social dimensions related to anaemia among women of childbearing age from rural India. Public Health Nutr 14(2): 365-372.

17. Nazir G, Naz S, Ali S, Aziz S, Malik SA, et al. (2011) Anaemia: the neglected female health problem in developing countries. J Ayub Med Coll Abbottabad JAMC 23(2): 8-11.

18. (2011) Government of Pakistan National Nutrition Survey, Pakistan.

19. Arif GM, Farooq S, Nazir S, Sathi M (2014) Child Malnutrition and Poverty: The Case of Pakistan. (C)The Pakistan Dev Rev 53(2): 99-118.

20. Singla PN, Tyagi M, Kumar A, Dash D, Shankar R (1997) Fetal growth in maternal anaemia. Journal of tropical pediatrics (43): 89-92.

21. Ahmad MO, Kalsoom U, Sughra U, Hadi U (2011) Effect of Maternal Anaemia on Birth Weight. J Ayub Med coll Abbottabad 23: 77-79.

22. Thuita FM, Mwadime RKN, Wangombe JK (2005) Child nutritional status and maternal factors in an urban slum in Nairobi, Kenya. East Afr Med J 82(4): 209-215.

23. Senbanjo IO, Olayiwola IO, Afolabi WA, Senbanjo OC (2013) Maternal and child under-nutrition in rural and urban communities of Lagos state, Nigeria: the relationship and risk factors. BMC Res Notes 6:1.

24. Addo OY, Stein AD, Fall CH, Gigante DP, Guntupalli AM, et al. (2013) Maternal height and child growth patterns. Vol. 163, Journal of Pediatrics 163(2): 549-554.

25. Yucel O, Dede Cinar N, Dede Çýnar N, Nursan Dede, Cinar C (2009) Maternal risk factors affecting newborn parameters. Pak J Med Sci Pak J Med SciPart-II) Pak J Med Sci 2525(33): 386-390.

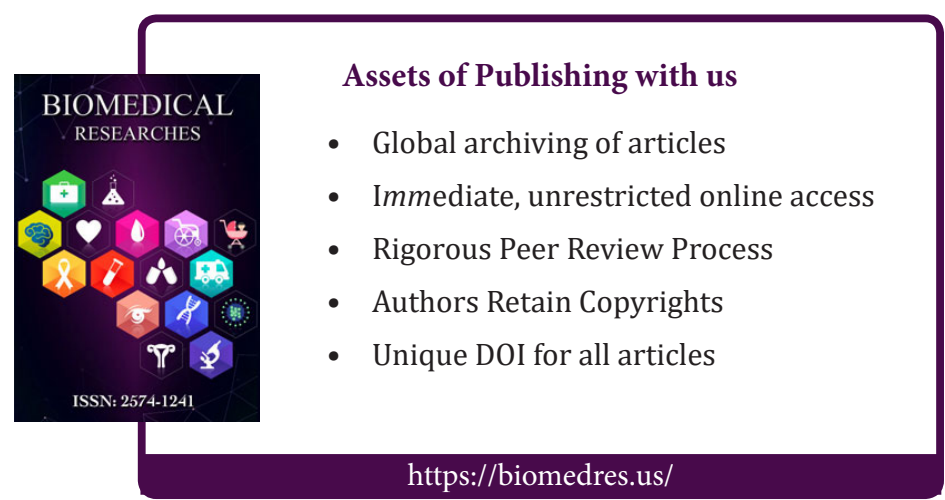

